\title{
Molecular cloning, expression, and subcellular localization of a $P A L$ gene from Citrus reticulata under iron deficiency
}

\author{
H.Y. YANG ${ }^{1}$, T. DONG ${ }^{2}$, J.F. LI ${ }^{3}$, and M.Y. WANG ${ }^{1}$ * \\ Department of Horticulture, Huaqiao University, Xiamen, P.R. China ${ }^{1}$ \\ Institute of Fruit Tree Research, Guangdong Academy of Agricultural Sciences, Guangzhou, P.R. China ${ }^{2}$ \\ School of Agriculture and Biology, Shanghai Jiaotong University, Shanghai, P.R. China ${ }^{3}$
}

\begin{abstract}
Phenylalanine ammonia lyase (PAL) is a specific branch point enzyme of primary and secondary metabolism. The Citrus reticulata Blanco PAL gene was cloned and designated as CrPAL1. The cDNA sequence of CrPAL1 was $2166 \mathrm{bp}$, encoding 721 amino acid residues. Sequence alignment indicates that $C r P A L 1$ shared a high identity with $P A L$ genes found in other plants. Both the dominant and catalytic active sites of $C r P A L 1$ were similar to PAL proteins observed in Petroselinum crispum. Phylogenetic tree analysis indicates that $\mathrm{CrPAL1}$ was more closely related to PALs in Citrus clementina $\times$ C. reticulata and Poncirus trifoliata than to those from other plants. Subcellular localization reveals that CrPAL1-green fluorescent protein fusion protein was specifically localized in the plasma membrane. Activity of PAL as well as CrPAL1 expression increased under Fe deficiency. A similar result was noted for total phenolic content. The root exudates of $C$. reticulata strongly promoted reutilization of apoplastic $\mathrm{Fe}$ in roots. Furthermore, $\mathrm{Fe}$ was more desorbed from the cell wall under Fe deficiency than in sufficient Fe supply.
\end{abstract}

Additional key words: phenolics, phenylalanine ammonia lyase, root exudation.

\section{Introduction}

Phenylalanine ammonia lyase (PAL, EC 4.3.1.5) is the first key enzyme of the phenylpropaniod pathway, which produces many important secondary metabolites including flavonoids, plant hormones, anthocyanins, lignins, phytoalexins, and many other important compounds in higher plants (Song and Wang 2009, Vogt 2010, Fraser and Chapple 2011). The PAL mediates a conversion of phenylalanine to cinnamic acid (Mandal et al. 2010, Zhang et al. 2013). So far, $P A L$ genes have been cloned from several plants including Arabidopsis thaliana (Cochrane et al. 2004), Pisum sativum, Nicotiana tabacum (Pellegrini et al. 1994), rice (Minami et al. 1989), and potato (Joos and Hahlbrock 1992).

Citrus reticulata Blanco is an important rootstock in nursery, and iron is essential for its growth and development (Kacar et al. 2014). Most citrus plants are cultivated in mountainous areas and are frequently challenged with iron deficiency (Pestana et al. 2012, Wulandari et al. 2014). The solubility of iron in soil is affected by $\mathrm{pH}$ and in soil with high $\mathrm{pH}, \mathrm{Fe}^{2+}$ is converted into $\mathrm{Fe}^{3+}$ and so it is less available. Moreover, a high $\mathrm{P}$ content reduces absorption of $\mathrm{Fe}$ (Brown 1980). Iron deficiency is a key limiting factor for fruit production and quality (Álvarez-Fernández et al. 2011), but C. reticulata is partially adapted to Fe deficiency through secretion of phenolic compounds to promote $\mathrm{Fe}$ solubilization (Zhang et al. 1991, Cesco et al. 2010).

Phenolic compounds are important secondary metabolites (Cesco et al. 2010) and PAL plays an important role in plant phenolic metabolism. Therefore, we cloned the full-length $P A L$ gene, studied the structure of it, and then investigated expression of the $P A L$ gene in Fe-deficient roots in parallel with analysis of PAL activity.

Submitted 3 September 2015, last revision 9 December 2015, accepted 14 December 2015.

Abbreviations: dd - double distilled; GFP - green fluorescent protein; ORF - open reading frame; PAL - phenylalanine ammonia lyase; qPCR - quantitative polymerase chain reaction.

Acknowledgments: The work was supported by the National Natural Science Foundation of China (31101512), the Subsidized Project for Cultivating Postgraduates' Innovative Ability in Scientific Research of the Huaqiao University, and the Research Funds of Fujian Forestry Science (Z1425063/3). The first two authors contributed equally to this work.

* Corresponding author; fax: (+86) 6162300, e-mail: w_mingyuan@163.com

This article is published with open access at link.springer.com 


\section{Materials and methods}

Plants and experimental design: Citrus reticulata Blanco seeds from the Huazhong Agricultural University were surface sterilized with $75 \%(\mathrm{v} / \mathrm{v})$ ethanol for $10 \mathrm{~min}$, rinsed with sterile double distilled water $\left(\mathrm{ddH}_{2} \mathrm{O}\right)$, placed on moist filter paper, and germinated in an incubator at $26^{\circ} \mathrm{C}$. River sand and Vermiculite (3:1, $\mathrm{v} / \mathrm{v})$ were cleaned with $1 \mathrm{M}$ hydrochloric acid to remove $\mathrm{Fe}$ ions and then autoclaved at $121{ }^{\circ} \mathrm{C}$ for $2 \mathrm{~h}$. Three uniform seedlings were transplanted to a $12 \mathrm{~cm}$ diameter plastic pot filled with $2.5 \mathrm{~kg}$ of the above substrate.

The experiment was a completely randomized design with two Fe treatments (Fe-sufficiency and Fe-deficiency) and each treatment had six replicates. The pots were irrigated twice a week with $200 \mathrm{~cm}^{3}$ of a half-strength Hoagland's nutrient solution according to Li et al. (2015). Iron was added as $o, o-F e E D D H A$ in two different concentrations: $50 \mu \mathrm{M}$ (Fe-sufficient treatment) and $0 \mu \mathrm{M}$ (Fe-deficient treatment). The nutrient solution $\mathrm{pH}$ was $6.0 \pm 0.1$. The seedlings were cultivated in a greenhouse under night/day temperatures of $16-18 / 26-28{ }^{\circ} \mathrm{C}$ and a natural irradiance and photoperiod. Eight weeks later, roots were harvested, immediately frozen in liquid nitrogen, and stored at $-80^{\circ} \mathrm{C}$.

Determination of total phenolics: Phenolics in root exudates from $C$. reticulata Blanco were extracted by the methods of $\mathrm{Xu}$ et al. (2007). The collected root exudates were evaporated to dryness and the residue was dissolved in methanol (Schieber et al. 2001). The total phenolic content was measured using the Folin-Ciocalteu method with absorbance measured at $765 \mathrm{~nm}$ using a spectrophotometer (UV-3600, Shimadzu, Japan) and compared with a gallic acid standard (Waterman and Mole 1994).

Desorption of Fe bound to the cell wall: The cell wall was extracted according to Zhong and Läuchli (1993) with modifications according to Li et al. (2015). The final pellet was freeze-dried overnight and the cell wall powder was stored at $4{ }^{\circ} \mathrm{C}$. The desorption kinetics of the root exudates was analyzed according to Jin et al. (2007). Approximately $0.05 \mathrm{~g}$ of the cell wall powder was added into a $2 \mathrm{~cm}^{3}$ column equipped with a filter at the bottom. The solution was run through using a peristaltic pump at a speed of $2 \mathrm{~cm}^{3}$ per $10 \mathrm{~min}$. It was then collected by a fraction collector at $10 \mathrm{~min}$ intervals, and $\mathrm{Fe}$ in the desorbed solutions was determined with 2,2-bipyridyl according to Bienfait et al. (1985). Finally, cumulative Fe desorbed was calculated and plotted against total desorption volumes.

Isolation of RNA and cDNA synthesis: The total RNA from frozen roots was extracted using an RNAprep pure tissue kit (Tiangen, Beijing, China). The DNA was removed using an RNAclean kit (Tiangen). Concentration, purity, and integrity of RNA were determined by spectrophotometric analysis $\left(\mathrm{A}_{260} / \mathrm{A}_{280}\right)$ and examined by electrophoresis on a $1.0 \%(\mathrm{~m} / \mathrm{v})$ agarose gel. The first-strand of cDNA was synthesized with a cDNA synthesis kit (TaKaRa, Dalian, China). The synthesized cDNA product was diluted appropriately and stored at $-20{ }^{\circ} \mathrm{C}$ until further analysis.

Cloning CrPAL1 cDNA: $C r P A L 1$ cDNA was obtained by reverse transcriptase-polymerase chain reaction. Specific primers (Table 1) were designed by the Primer Premier 5.0 software based on a multiple sequence alignment of the known PAL sequences of Citrus sinensis, Citrus clementina $\times$ Citrus reticulata, and other plants in GenBank. The primers were synthesized by Sangon Biotechnology Co. (Shanghai, China). The PCR reaction was carried out in a final volume of $50 \mathrm{~mm}^{3}$ containing $5 \mathrm{~mm}^{3}$ of $10 \times$ Ex Taq buffer $\left(\mathrm{Mg}^{2+}\right.$ plus), $4 \mathrm{~mm}^{3}$ of $2.5 \mathrm{mM}$ each dNTP mixture, $2 \mathrm{~mm}^{3}$ of each primer, $40 \mathrm{ng}$ of template, $0.5 \mathrm{~mm}^{3}$ of TaKaRa Ex Taq $\left(5 \mathrm{U} \mathrm{mm}^{-3}\right)$ and $36.5 \mathrm{~mm}^{3}$ of $\mathrm{ddH}_{2} \mathrm{O}$. Conditions for PCR were: $94^{\circ} \mathrm{C}$ for $5 \mathrm{~min}, 30$ cycles $\left(94^{\circ} \mathrm{C}\right.$ for $30 \mathrm{~s}, 55^{\circ} \mathrm{C}$ for $30 \mathrm{~s}, 72^{\circ} \mathrm{C}$ for $2.5 \mathrm{~min}$ ), and $72{ }^{\circ} \mathrm{C}$ for $7 \mathrm{~min}$. The PCR products were purified and transformed into $E$. coli strain DH5 $\alpha$ competent cells using the $p M D-18 T$ vector $($ TaKaRa). The transformed cells were inoculated on a solid selection lysogeny broth (LB) medium containing $\mathrm{X}$-Gal, isopropyl- $\beta$-d-thiogalactoside (IPTG), and ampicillin. White positive colonies were cultured in liquid LB media for $16 \mathrm{~h}$ to extract plasmids, which were purified and sequenced by Sangon Biotechnology Co.

Sequence analysis: The vector NTI Advance ${ }^{@} 11.5$ was used to translate an open reading frame (ORF), align sequences, and calculate the molecular mass of the predicted protein. Multiple alignment analysis was performed by Clustal W. BLAST via NCBI (http://www. ncbi.nlm.nih.gov/). The website of Expasy Molecular Biology Server (http://www.cn.expasy.org/tools/) was used to analyze the structure of the predicted PAL protein. Homology-based structure modelling was done with Swiss-Model (Guex and Peitsch 1997). The transcription start site was forecast by the Neural Network Promoter Prediction software (http://www. fruitfly.org/seq_tools/promoter.html). Web Lab View Lite 4.0 was used to display 3-D structures. Phylogenetic analysis was built using the MEGA 5.1 software by the neighbor-joining method.

Subcellular localization: For generation of CrPAL1mGFP5, the ORF of the CrPAL1 cDNA was PCR amplified using respective primers (Table 1). The fragment was cloned into CrPAL1-mGFP5 under control of the CaMV35 promoter of pCAMBIA1302. Agrobacterium strain GV3101 carrying the constructs was grown overnight in a Murashige and Skoog solid 
medium containing $50 \mu \mathrm{g} \mathrm{cm}^{-3}$ kanamycin and $50 \mu \mathrm{g} \mathrm{cm}^{-3}$ rifampicin. The fusion expression vector (pCAMBIA1302-CrPAL1) was transformed into the inner epidermis of onion (Allium cepa). For comparison, pCAMBIA1302 was transiently expressed in the inner epidermis of onion. Green fluorescent protein (GFP) was visualized using an LSM 5 Exciter confocal laser scanning microscope (LSM 710, Carl-Zeiss, Germany) with excitation at $488 \mathrm{~nm}$ and emission at 505 to $530 \mathrm{~nm}$ (Du et al. 2012).

Determination of PAL activity: Fresh roots $(100 \mathrm{mg})$ were ground with $2.0 \mathrm{~cm}^{3}$ of a solution containing $50 \mathrm{mM}$ phosphate buffer ( $\mathrm{pH} 7.0), 1 \%(\mathrm{~m} / \mathrm{v})$ polyvinylpolypyrrolidone, and $0.2 \mathrm{mM}$ ascorbic acid. After centrifugation at $4000 \mathrm{~g}$ and $4{ }^{\circ} \mathrm{C}$ for $15 \mathrm{~min}$, the supernatant was spectrometrically $(U V-3600$, Shimadzu) analyzed for PAL activity at $290 \mathrm{~nm}$ using L-phenylalanine (SigmaAldrich, St. Louis, MO, USA) as substrate (Boo et al. 2011).

Expression analysis of CrPAL1 by real time quantitative PCR (qPCR) was conducted using an
Applied Biosystems 7500 system (Foster City, CA, USA) in roots under Fe-deficiency. Specific primersfor $C r P A L 1$ and $\beta$-actin (Table 1) were designed using the Primer Premier 5.0 software and synthesized by Sangon Biotechnology Co. A $25 \mathrm{~mm}^{3}$ of a reaction mixture contained $12.5 \mathrm{~mm}^{3}$ of MightyAmp real time (SYBR Plus), $0.5 \mathrm{~mm}^{3}$ of a PCR forward primer $(10 \mu \mathrm{M})$, $0.5 \mathrm{~mm}^{3}$ of a PCR reverse primer $(10 \mu \mathrm{M}), 2 \mathrm{~mm}^{3}$ of a template, and $9.5 \mathrm{~mm}^{3}$ of $\mathrm{ddH}_{2} \mathrm{O}$. The PCR program was: the first cycle at $95^{\circ} \mathrm{C}$ for $30 \mathrm{~s}$ followed by 40 cycles of $5 \mathrm{~s}$ at $95^{\circ} \mathrm{C}, 45 \mathrm{~s}$ at $60^{\circ} \mathrm{C}$, and a final extension at $72{ }^{\circ} \mathrm{C}$ for $30 \mathrm{~s}$. Melting curve analysis was performed under the following conditions: $10 \mathrm{~s}$ at $70{ }^{\circ} \mathrm{C}$ and heating to $100{ }^{\circ} \mathrm{C}$ at a rate of $0.2{ }^{\circ} \mathrm{C} \mathrm{s}^{-1}$. The actin gene was chosen as reference under the same conditions. The relative expression of the $P A L$ gene was calculated by the $2^{-\Delta \Delta} \mathrm{Ct}$ method (Livak and Schmittgen 2001).

Statistical analysis: All data were subjected to one-way ANOVA using the $S A S$ v. 8.0 software (SAS Institute Inc., Cary, USA). Significant differences between treatments were determined by one-way $A N O V A$ at $P<0.05$.

Table 1. Specific primers designed for cloning and real time quantitative PCR amplification.

\begin{tabular}{lllr}
\hline Gene name & Sequence $(5,-3$ ') - forward & Sequence (5', 3') - reverse & Product size [bp] \\
\hline$P A L$ & ATGGACAGAGGTGCTGTTATTGAG & CTAGTGCATATTGGAAGAGGGGC & 2166 \\
$P A L-T F$ & AGATGTAAACTCCTTGGACTGA & CGACGGTTAAGACTTTCTAGCT & 188 \\
$\beta$-actin & CACACTGGAGTGATGGTTGG & ATTGGCCTTGGGGTTAAGAG & 228 \\
ORF & ATGGACAGAGGTGCTGTTATTGAG & GTGCATATTGGAAGAGGGGC & 2166 \\
\hline
\end{tabular}

\section{Results}

Total phenolic content under the Fe-deficiency was $8.45 \mu \mathrm{g} \mathrm{g}^{-1}$ (root exudates), which was significantly higher

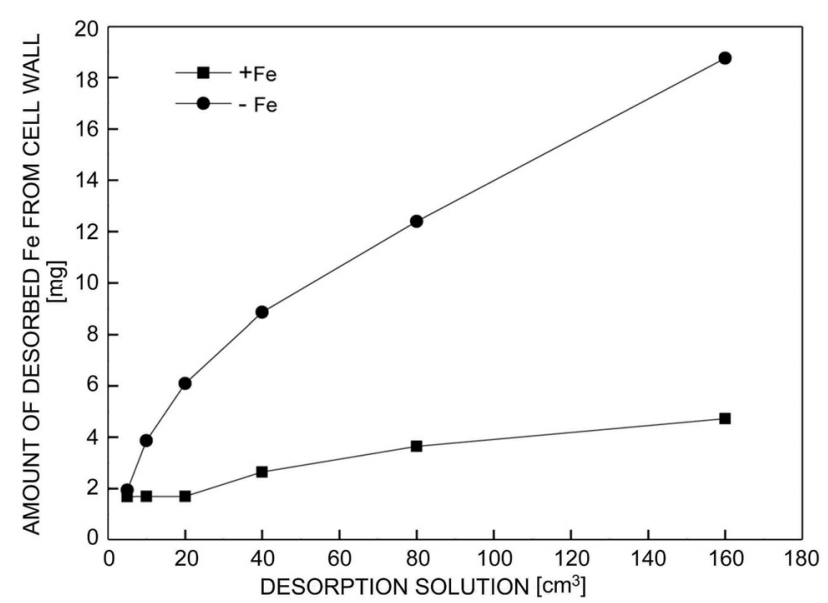

Fig. 1. The desorption kinetic curve of Fe in root cell walls of Citrus reticulata under Fe-deficiency (-Fe) and Fe-sufficiency $(+\mathrm{Fe})$. than in the Fe-sufficient treatment $\left[4.87 \mu \mathrm{g} \mathrm{g}^{-1}\right.$ (root exudates); Table 2]. The content of desorbed Fe increased almost linearly with the volume of the desorption solution (from 40 to $160 \mathrm{~cm}^{3}$; Fig. 1). Only a small amount of apoplastic $\mathrm{Fe}$ was desorbed from the cell wall under Fe-sufficiency, and the content of desorbed $\mathrm{Fe}$ was obviously higher under the Fe-deficiency than under the Fe-sufficiency.

Based on the known $P A L$ sequences of $C$. sinensis, $C$. clementina $\times C$. reticulata, and other plants in GenBank, the full-length sequence of PAL1 was obtained by the method of homology cloning from $C$. reticulata. This sequence was named CrPAL1 (GenBank accession No. KP742840). The full-length cDNA of CrPAL1 was 2166 bp (Fig. 2). The ORF encoded a protein with 721 amino acids with a predicted molecular mass of $78.6 \mathrm{kDa}$ and a pI of 6.09. BLAST analysis reveals that the deduced amino acid sequence of the CrPAL1 protein shared two highly conserved deamination sites and a typical phenylalanine/histidine ammonia lyase protein tag 
(Fig. 1 Suppl.). CrPAL1 exhibited a high homology with Populus trichocarpa (AFZ78650.1), Daucus carota (BAC56977.1), Vitis vinifera (AEX32784.1), Litchi chinensis (ACR15762.1), Jatropha curcas (ABI33979.1), Ricinus communis (AGY49231.1), and Citrus clementina $\times$ Citrus reticulata (CAB42793.1). Furthermore, the results show that CrPAL1 included conserved deamination sites: L213, V214, L261, and A262; and conserved catalytic active sites: N265, G266, NDN (387389 aa), H401, and HNQDV (491-495 aa) (Fig. 3 Suppl.).

The secondary structure was predicted. The CrPAL1 protein mainly included an alpha helix $(48.13 \%)$ and a random coil $(28.99 \%)$, whereas an extended strand $(13.04 \%)$ and a beta turn $(9.85 \%)$ contributed little to the structure (Fig. 4 Suppl.). The predicted threedimensional structure of the CrPAL1 protein was performed using Swiss-Model with the Petroselinum crispum PAL protein structure as template (Fig. 3). Average sequence similarities between $\operatorname{CrPAL1}$ and a $P$. crispum PAL homologue were $83.07 \%$. The CrPAL1 protein was assumed a 'sea horse' shape.

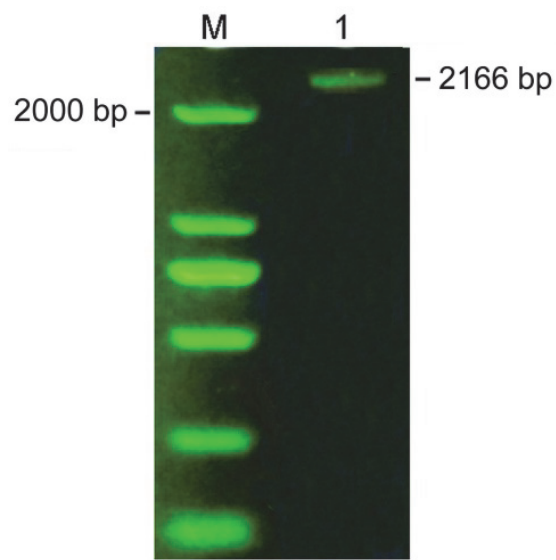

Fig. 2. The full length cDNA of $C r P A L 1 . \mathrm{M}-2 \mathrm{~kb}$ DNA maker; 1 - $\operatorname{Cr} P A L 1$ fragment.

In order to evaluate the structural characteristics of the $P A L$ genes in $C$. reticulata, the amino acids were aligned with the PAL proteins from other plants by MEGA 5.0 analysis. A neighbor-joining phylogenetic tree was divided into three main branches comprising dicotyledons, monocotyledons, and gymnosperms (Fig. 4), which is in accord with a traditional taxonomic classification. The results demonstrate that $\operatorname{CrPAL1}$ was most close to the $P A L$ gene of $P$. trifoliata and $C$. clementina $\times$ C. reticulata. Our results also show that $C r P A L 1$ shared the same ancestor.

\section{Discussion}

Citrus is one of the most economically important fruit plants in China. It is cultivated in mountainous areas

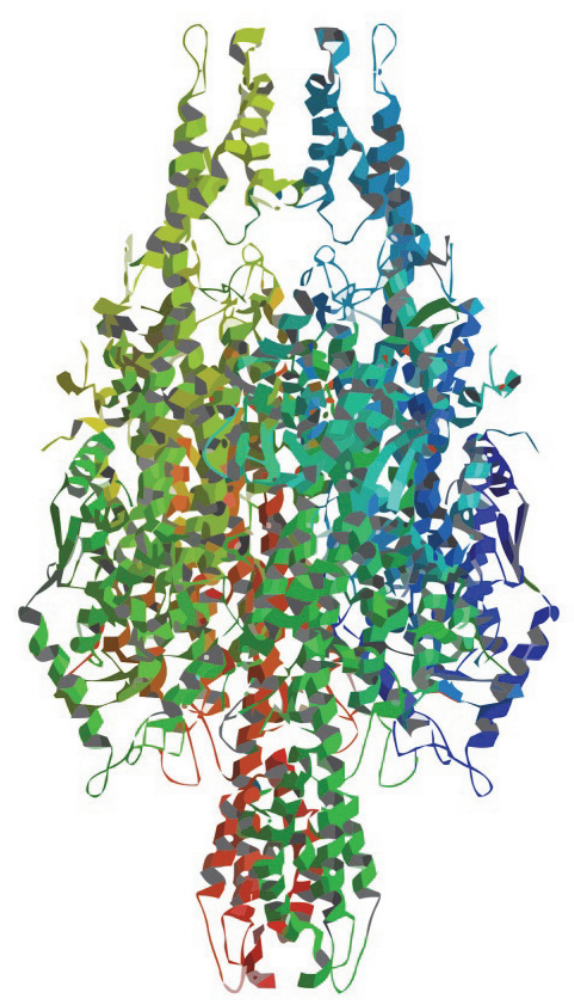

Fig. 3. A schematic illustration of the 3-D structure of the CrPAL1 protein designed using the crystal structure of Petroselinum crispum phenylalanine ammonia lyase as template.

The subcellular location of the CrPAL1 protein was analyzed using the GFP as reporter in transient expression assays, and bacterial cells carying CrPAL1$m G F P 5$ plasmids were infiltrated into the epidermal cells of onion. Confocal microscopy images demonstrate that the CrPAL1-mGFP5 fusion protein was specifically distributed in the plasma membrane, whereas the GFP alone showed a ubiquitous distribution in the whole cell (Fig. 5). These results suggest that CrPAL1 was a membrane-localized protein.

The PAL activity was analyzed by UV spectrophotometry. The results show that PAL activity was significantly higher (by $16.02 \%$ ) under the Fe deficiency than under the Fe sufficiency.

Real time qPCR reveals that expression of the $P A L$ gene was affected by the Fe deficiency. Expression of the $P A L 1$ gene in Fe-deficient roots was significantly higher (1.33 times) than that measured in Fe-sufficient roots (Table 2).

where Fe deficiency is a primary limiting factor for citrus production (Bao et al. 2006). Citrus reticulata is 
important rootstock of citrus cultivars. Thus, research on the $P A L$ gene encoding enzyme that is responsible for biosynthesis of phenolics is essential. In this paper, the full-length cDNA of CrPAL1 was cloned from Citrus reticulata using reverse transcriptase PCR. CrPAL1 encoded a protein with 721 amino acids; its length was similar to that reported for other PALs (Sanchez-Ballesta et al. 2000). The sequence alignment shows $C r P A L 1$ was highly similar to other known $P A L$ genes, as to those found in Poncirus trifoliata, C. sinensis, C. limon, C. clementina $\times C$. reticulata, and Vitis vinifera originating from the same branch in the phylogenic tree.
Meanwhile, classical PAL domains and functional sites were found in the deduced PAL protein, such as the conserved deamination sites: L213, V214, L261, and A262; and the conserved catalytic active sites: N265, G266, NDN (387-389 aa), H401, and HNQDV (491-495 aa). These sites are known to be highly conserved in different plants (Song and Wang 2009). In addition, the CrPAL1 protein has a typical protein tag of phenylalanine or histidine ammonia lyase (Ritter and Schulz 2004) suggesting that the deduced amino acid sequence of CrPAL1 was accurate. All the active sites mentioned above were the same with those of $P A L$ mentioned

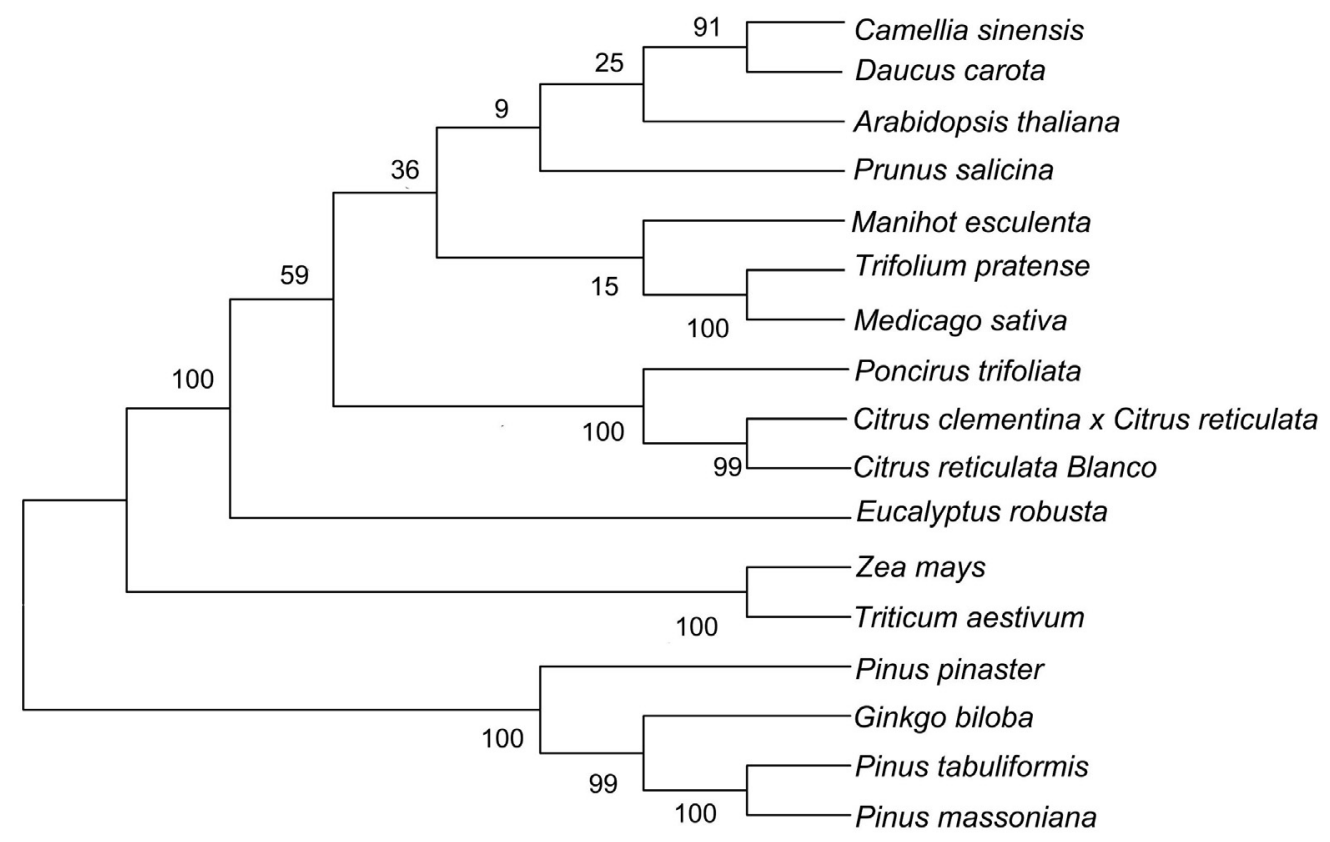

Fig. 4. The phylogenetic analysis of CrPAL1 with other PAL sequences from Pinus tabuliformis (AFR79235.1), P. massoniana (ACS28225.2), Ginkgo biloba (ABU49842.1), P. pinaster (CBC83356.1), Zea mays (AFW72411.1), Triticum aestivum (CAA68036.1), Citrus clementina $\times$ Citrus reticulata (CAB42793.1), Manihot esculenta (AAK62030.1), Prunus salicina (AFP24940.1), Camellia sinensis (P45726.1), Daucus carota (BAG31930.1), Trifolium pratense (AAZ29732.1), Medicago sativa (CAA41169.1), and Arabidopsis thaliana (AAC18870.1).

by $\mathrm{Xu}$ et al. (2012), indicating that CrPAL1 is member of the $P A L$ gene family.

The subcellular localization of the PAL protein has been studied in different plants (Czichi and Kindl 1975, Hrazdina and Wagner 1985, Rasmussen and Dixon 1999, Achnine et al. 2004, Sato et al. 2004, Bassard et al. 2012). In the present study, the subcellular localization of the CrPAL1 protein was investigated in a heterologous system (the chloroplast-free epidermal cells of onion) by confocal laser-scanning microscopical imaging GFPfluorescence. A transient expression of the CrPAL1mGFP5 fusion protein in onion was targeted to the plasma membrane. The result might indicate a high association of the CrPAL1 protein to membranes.

Studies that plant enzymes are involved in phenolic compound syntheses have been associated with plant stress. Phenylalanine ammonia lyase is a well

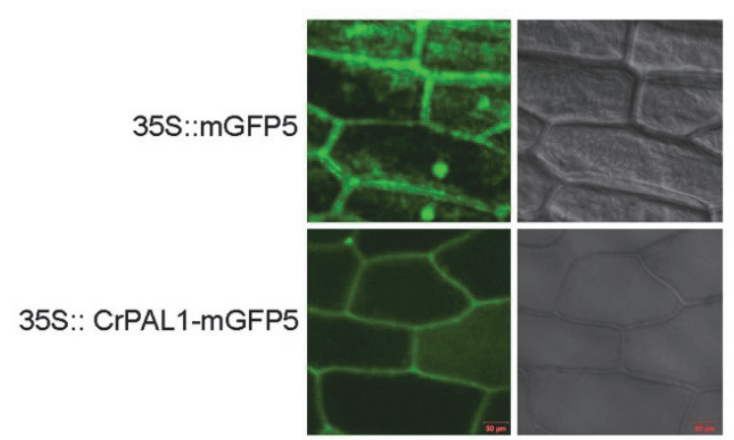

Fig. 5. The subcellular localization of the CrPAL1 protein. Green fluorescent protein fluorescence in onion epidermal cells transfected with a recombinant vector 35S::CrPAL1-mGFP5 and with the empty vector 35S::mGFP5. Time course images were obtained by confocal microscopy after agro-infiltration. Dark- and bright-field images are shown. 
characterized and key limiting enzyme in the phenylpropanoid pathway (Huang et al. 2010). In this experiment, we observed that PAL activity significantly increased under the Fe-deficiency (Table 2). These results are in agreement with recent studies that have shown higher PAL activities in other Fe-deficient plants (Li et al. 2015). Consequently, the enhancement of PAL activity promoted accumulation of phenolic compounds to promote Fe solubilization.

Table 2. The impact of iron deficiency on activity of phenylalanine ammonia lyase, relative CrPAL1 mRNA abundance, and the total phenolic content in C. reticulata roots. Means \pm SEs of three biological replicates. Statistical significance of differences was determined $(P<0.05)$ by Students $t$-tests and marked with asterisks.

\begin{tabular}{lrr}
\hline & Fe sufficient & Fe deficient \\
\hline PAL activity $\left[\mathrm{U} \mathrm{g}^{-1}\right.$ (f.m.) $]$ & $128.50 \pm 6.10$ & $149.09 \pm 7.50^{*}$ \\
Relative mRNA abundance & $1.00 \pm 0.23$ & $1.33 \pm 0.10^{*}$ \\
Phenolic content $\left[\mu \mathrm{g} \mathrm{g}^{-1}\right.$ (f.m.) $]$ & $4.87 \pm 0.29$ & $8.45 \pm 0.51^{*}$
\end{tabular}

Furthermore, the $\mathrm{Fe}$ deficiency promoted gene expression related to phenolic compound synthesis. Owing to its important role, the $P A L$ gene was widely studied in different tissues of plants since its discovery. In this paper, real time qPCR analysis reveals that a high CrPAL1 expression was found in roots (Table 2). Expression of the $P A L$ gene in roots could be induced by different abiotic stimulation, such as low content of nitrogen, phosphate and iron, or by signalling compounds such as methyl jasmonate, jasmonic acid, $\mathrm{H}_{2} \mathrm{O}_{2}$, and salicylic acid (Hsieh et al. 2011). Studies have also discovered that the total amount of phenolic compounds was higher under Fe deficiency (Hell and Stephan 2003). Thus, expression of CrPAL1 was up-regulated in response to the Fe deficiency, which is consistent with observations of other plants under stress conditions (Wasternack and Parthier 1997). So, this may explain that activation of secondary metabolism is important for successful plant growth under iron stress.

In conclusion, we cloned one $P A L$ gene from Citrus reticulata Blanco and designated it $\operatorname{CrPAL1}$. Regardless of the fact that the functional details of $\operatorname{CrPAL1}$ are still unclear, its sequence characterization and induced expression in response to a low content of iron suggest that $C r P A L 1$ might participate in stress response pathways. Thus, CrPAL1 could be considered as a potential target gene to be used in genetic engineering for creation of transgenic plants with improved stress tolerance.

This article is distributed under the terms of the Creative Commons Attribution License which permits any use, distribution, and reproduction in any medium, provided the original author(s) and the source are credited.

\section{References}

Achnine, L., Blancaflor, E.B., Rasmussen, S., Dixon, R.A.: Colocalization of L-phenylalanine ammonia-lyase and cinnamate 4-hydroxylase for metabolic channeling in phenylpropanoid biosynthesis. - Plant Cell 16: 3098-3109, 2004.

Álvarez-Fernández, A., Melgar, J.C., Abadia, J., Abadia, A.: Effects of moderate and severe iron deficiency chlorosis on fruit yield, appearance and composition in pear (Pyrus communis L.) and peach (Prunus persica (L.) Batsch). Environ. exp. Bot. 71: 280-286, 2011.

Bao, J.F., Xia, R.X., Peng, S.A., Li, G.H.: Main soil nutrient status of newhall orchards of Hubei province and its effect on fruit quality of newhall orange. - Soils 38: 75-80, 2006.

Bassard, J.E., Mutterer, J., Duval, F., Werck-Reichhart, D.: A novel method for monitoring the localization of cytochromes $\mathrm{P}_{450}$ and other endoplasmic reticulum membrane associated proteins: a tool for investigating the formation of metabolons. - FEBS J. 279: 1576-1583, 2012.

Bienfait, H.F., Briel, W.V.D., Mesland-Mul, N.T.: Free space iron pools in roots generation and mobilization. - Plant Physiol. 78: 596-600, 1985.

Boo, H.O., Heo, B.G., Gorinstein, S., Chon, S.U.: Positive effects of temperature and growth conditions on enzymatic and antioxidant status in lettuce plants. - Plant Sci. 181: 479-484, 2011.

Brown R.: Factors related to iron uptake by dicotyledonous and monocotyledonous plants. 11. The reduction of $\mathrm{Fe}^{3+}$ as influenced by roots and inhibitors. - J. Plant Nutr. 2: 647$660,1980$.

Cesco, S., Neumann, G., Tomasi, N., Pinton, R., Weisskopf, L.: Release of plant-borne flavonoids into the rhizosphere and their role in plant nutrition. - Plant Soil 329: 1-25, 2010.

Cochrane, F.C., Davin, L.B., Lewis, N.G.: The Arabidopsis phenylalanine ammonia lyase gene family: kinetic characterization of the four $P A L$ isoforms. - Phytochemistry 65: 1557-1564, 2004.

Czichi, U., Kindl, H.: Formation of $p$-coumaric acid and $o$ coumaric acid from L-phenylalanine by microsomal membrane fractions from potato: evidence of membranebound enzyme complexes. - Planta 125: 115-125, 1975.

Du, S.C., In, S.H., Byung, K.H.: Requirement of the cytosolic interaction between pathogenesis-related protein 10 and leucine-rich repeat protein1 for cell death and defense signaling in pepper. - Plant Cell 24: 1675-1690, 2012.

Fraser, C.M., Chapple, C.: The phenylpropanoid pathway in Arabidopsis. - The Arabidopsis Book. 9: e0152, 2011.

Guex, N., Peitsch, M.C.: Swiss-Model and the Swiss-Pdb Viewer: an environment for comparative protein modeling. - Electrophoresis 18: 2714-2723, 1997.

Hell, R., Stephan, U.W.: Iron uptake, trafficking and homeostasis in plants. - Planta 216: 541-551, 2003.

Hrazdina, G., Wagner, G.J.: Metabolic pathways as enzyme 


\section{H.Y. YANG et al.}

complexes: evidence for the synthesis of phenylpropanoids and flavonoids on membrane associated enzyme complexes. - Arch. Biochem. Biophys. 237: 88-100, 1985.

Hsieh, L.S., Hsieh, Y.L., Yeh, C.S., Cheng, C.Y., Yang, C.C., Lee, P.D.: Molecular characterization of a phenylalanine ammonia-lyase gene (BoPAL1) from Bambusa oldhamii. Mol. Biol. Rep. 38: 283-290, 2011.

Huang, J.L., Gu, M., Lai, Z.B., Fan, B.F., Shi, K., Zhou, Y.H., Yu, J.Q., Chen, Z.X.: Functional analysis of the Arabidopsis $P A L$ gene family in plant growth, development, and response to environmental stress. - Plant Physiol. 153: 1526-1538, 2010.

Jin, C.W., You, G.Y., He, Y.F., Tang, C., Wu, P., Zheng, S.J.: Iron deficiency-induced secretion of phenolics facilitates the reutilization of root apoplastic iron in red clover. - Plant Physiol. 144: 278-285, 2007.

Joos, H.J., Hahlbrock, K.: Phenylalanine ammonia-lyase in potato (Solanum tuberosum L.). - Eur. J. Biochem. 204: 621-629, 1992.

Kacar, Y.A., Simsek, O., Donmez, D., Boncuk, M., Yesiloglu, T., Ollitrault, P.: Genetic relationships of some Citrus genotypes based on the candidate iron chlorosis genes. Turk. J. Agr. Forest. 38: 340-347, 2014.

Li, J.F., Zheng, W.J., Zeng, L., Liu, J.F., Wang, M.Y.: Molecular cloning, expression and sequence analysis of a phenylalanine ammonia-lyase gene from Poncirus trifoliata under iron deficiency. - Aust. J. Bot. 62: 698-704, 2015.

Livak, K.J., Schmittgen, T.D.: Analysis of relative gene expression data using real-time quantitative PCR and the $2^{-\Delta \Delta \mathrm{CT}}$ method. - Methods 25: 402-408, 2001.

Mandal, S.M., Chakraborty, D., Dey, S.: Phenolic acids act as signaling molecules in plant-microbe symbioses. - Plant Signal. Behav. 5: 359-368, 2010.

Minami, E.I., Ozeki, Y., Matsuoka, M., Koizuka, N., Tanaka, Y.: Structure and some characterization of the gene for phenylalanine ammonia-lyase from rice plants. - Eur. J. Biochem. 185: 19-25, 1989.

Pellegrini, L., Rohfritsch, O., Fritig, B., Legrand, M.: Phenylalanine ammonia-lyase in tobacco - molecular cloning and gene expression during the hypersensitive reaction to tobacco mosaic virus and the response to a fungal elicitor. - Plant Physiol. 106: 877-886, 1994.

Pestana, M., Gama, F., Saavedra, T., De Varennes, A., Correia, P.J.: The root ferric-chelate reductase of Ceratonia siliqua (L.) and Poncirus trifoliata (L.) Raf. responds differently to a low level of iron. - Sci. Hort. 135: 65-67, 2012.

Rasmussen, S., Dixon, R.A.: Transgene-mediated and elicitorinduced perturbation of metabolic channeling at the entry point into the phenylpropanoid pathway. - Plant Cell 11: 1537-1551, 1999.
Ritter, H., Schulz, G.E.: Structural basis for the entrance into the phenylpropanoid metabolism catalyzed by phenylalanine ammonia-lyase. - Plant Cell 16: 3426-3436, 2004.

Sanchez-Ballesta, M.T., Lafuente, M.T., Zacarias, L., Granell, A.: Involvement of phenylalanine ammonia-lyase in the response of Fortune mandarin fruits to cold temperature. Physiol Plant. 108: 382-389, 2000.

Sato, T., Takabe, K., Fujita, M.: Immunolocalization of phenylalanine ammonia-lyase and cinnamate-4-hydroxylase in differentiating xylem of poplar. - Compt. rend. Biol. 327: 827-836, 2004.

Schieber, A., Keller, P., Carle, R.: Determination of phenolic acids and flavonoids of apple and pear by high-performance liquid chromatography. - J. Chromatogr. A 910: 265-273, 2001.

Song, J., Wang, Z.: Molecular cloning, expression and characterization of a phenylalanine ammonia-lyase gene (SmPAL1) from Salvia miltiorrhiza. - Mol. Biol. Rep. 36: 939-952, 2009.

Vogt, T.: Phenylpropanoid biosynthesis. - Mol. Plants 3: 2-20, 2010.

Wasternack, C., Parthier, B.: Jasmonate-signalled plant gene expression. - Trends Plant Sci. 2: 302-307, 1997.

Waterman, P.G., Mole, S.: Analysis of Phenolic Plant Metabolites. - Blackwell Scientific, Oxford - London 1994.

Wulandari, C., Muraki, S., Hisamura, A., Ono, H., Honda, K., Kashima, T., Subandiyah, S.: Effect of iron deficiency on root ferric chelate reductase, proton extursion, biomass production and mineral absorption of citrus root stock orange jasmine (Murraya exotica L.). - J. Plant Nutr. 37: 50-64, 2014.

Xu, F., Deng, G., Cheng, S.Y., Zhang, W.W., Huang, X.H., Li, L.L., Cheng, H., Rong, X.F., Li, J.B.: Molecular cloning, characterization and expression of the phenylalanine ammonia-lyase gene from Juglans regia. - Molecules 17: 7810-7823, 2012.

Xu, W.H., Liu, H., Ma, Q.F., Xiong, Z.T.: Root exudates, rhizosphere $\mathrm{Zn}$ fractions, and $\mathrm{Zn}$ accumulation of ryegrass at different soil Zn levels. - Pedosphere 17: 389-396, 2007.

Zhang, F.S., Römheld, V., Marschner, H.: Role of the root apoplasm for iron acquisition by wheat plants. - Plant Physiol. 97: 1302-1305, 1991.

Zhang, R.Q., Zhu, H.H., Zhao, H.Q., Yao, Q.: Arbuscular mycorrhizal fungal inoculation increases phenolic synthesis in clover roots via hydrogen peroxide, salicylic acid and nitric oxide signaling pathways. - J. Plant Physiol. 170: 7479, 2013.

Zhong, H., Läuchli, A.: Changes of cell wall composition and polymer size in primary roots of cotton seedlings under high salinity. - J. exp. Bot. 44: 773-778, 1993. 